\title{
Strength investigation of thick welded T-Joint using finite element modelling
}

\begin{abstract}
The paper discusses the computation of finite element modelling (FEM) of a thick welded joint as a high load transfer joint. The FEM utilises MSC PATRAN/NASTRAN software programs to predict and simulate the critical area of a welded joint. The elasticity limit for the specimen was determined and stress distribution was achieved in the joint to indicate critical parts of a welded T-joint and predict the critical locations for crack initiation in this kind of joint. Simulation and experimental results show good in agreement and the sources of some differences in these results are discussed.
\end{abstract}

Keyword: T-joints, finite element modelling, FEM, MSC PATRAN, Welded T-joints, MSC NASTRAN 